\title{
Nuclear Energy Infrastructure Database Fitness and Suitability Review
}

\author{
Brenden Heidrich, Chair
} NEID Database Review Panel

March 2015

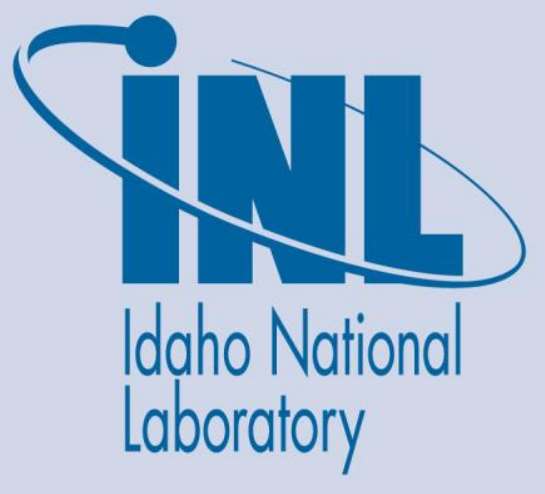

The INL is a U.S. Department of Energy National Laboratory operated by Battelle Energy Alliance 


\section{DISCLAIMER}

This information was prepared as an account of work sponsored by an agency of the U.S. Government. Neither the U.S. Government nor any agency thereof, nor any of their employees, makes any warranty, expressed or implied, or assumes any legal liability or responsibility for the accuracy, completeness, or usefulness, of any information, apparatus, product, or process disclosed, or represents that its use would not infringe privately owned rights. References herein to any specific commercial product, process, or service by trade name, trade mark, manufacturer, or otherwise, does not necessarily constitute or imply its endorsement, recommendation, or favoring by the U.S. Government or any agency thereof. The views and opinions of authors expressed herein do not necessarily state or reflect those of the U.S. Government or any agency thereof. 
INL/EXT-15-34453

Revision 1

\title{
Nuclear Energy Infrastructure Database Fitness and Suitability Review
}

\author{
Brenden Heidrich, Chair \\ NEID Database Review Panel
}

March 2015

\begin{abstract}
Idaho National Laboratory Nuclear Scientific User Facilities Idaho Falls, Idaho 83415
\end{abstract}

http://www.inl.gov

Prepared for the

U.S. Department of Energy

Office of Nuclear Energy

Under DOE Idaho Operations Office

Contract DE-AC07-05ID14517 

Nuclear Scientific User Facilities

\title{
Nuclear Energy Infrastructure Database Fitness and Suitability Review
}

\author{
INL/EXT-15-34453 \\ Revision 1 \\ March 2015
}

Prepared by:

Brenden Heidrich

Date

Nuclear Energy R\&D Infrastructure Lead

Approved by:

Rory Kennedy

Director, NSUF

Date 



\section{SUMMARY}

In 2014, the Deputy Assistant Secretary for Science and Technology Innovation initiated the Nuclear Energy-Infrastructure Management Project by tasking the Nuclear Science User Facilities, formerly the Advanced Test Reactor National Scientific User Facility, to create a searchable and interactive database of all pertinent nuclear energy (NE)-supported or related infrastructure. This database will be used for analyses to establish needs, redundancies, efficiencies, distributions, etc., to best understand the utility of NE's infrastructure and inform the content of the infrastructure calls. The Nuclear Science User Facilities developed the database by utilizing data and policy direction from a variety of reports from the Department of Energy, the National Research Council, the International Atomic Energy Agency, and various other federal and civilian resources. The Nuclear Energy Infrastructure Database currently contains data on 802 research and development instruments housed in 377 facilities at 84 institutions in the U.S. and abroad.

A Database Review Panel was formed to review and provide advice on the development, implementation, and utilization of the Nuclear Energy Infrastructure Database. The panel is comprised of five members with expertise in NE-associated research. It was intended that they represent the major constituencies associated with NE research: academia, industry, research reactor, national laboratory, and Department of Energy program management. The Nuclear Energy Infrastructure Database Review Panel concludes that the Nuclear Science User Facilities has succeeded in creating a capability and infrastructure database that identifies and documents the major NE research and development capabilities across the Department of Energy complex. The effort to maintain and expand the database will be ongoing. Detailed information on many facilities must be gathered from associated institutions added to complete the database. The data must be validated and kept current to capture facility and instrumentation status as well as to cover new acquisitions and retirements. 


\section{CONTENTS}

1. PURPOSE OF THE NUCLEAR ENERGY-INFRASTRUCTURE MANAGEMENT

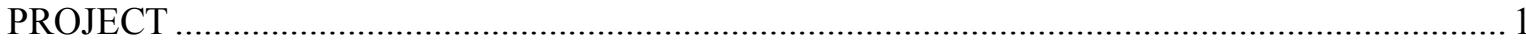

2. DESCRIPTION OF THE NUCLEAR ENERGY INFRASTRUCTURE DATABASE

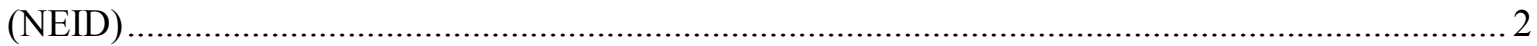

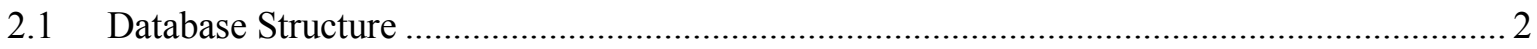

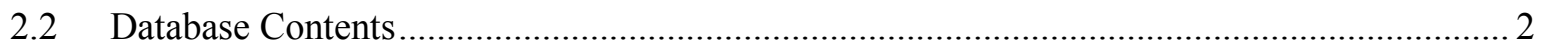

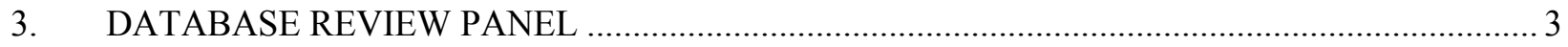

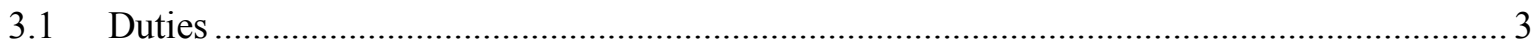

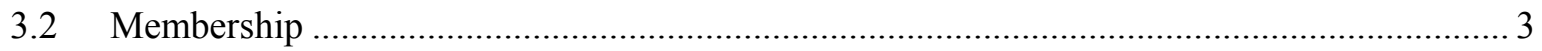

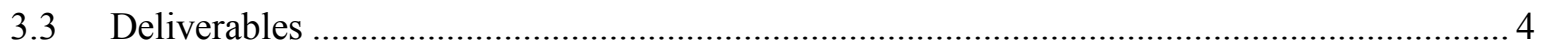

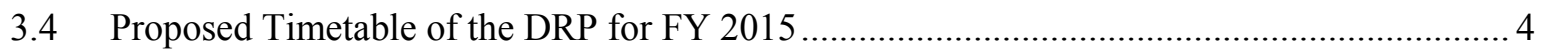

4. REVIEW COMMENTS FROM THE NEID DATABASE REVIEW PANEL ............................. 5

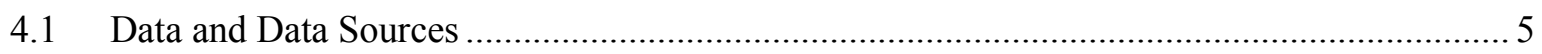

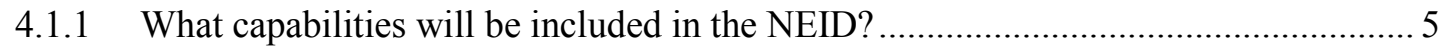

4.1.2 How will the data in the NEID be kept current? .................................................... 7

4.1.3 What sources were used to initially populate the NEID? ..................................... 8

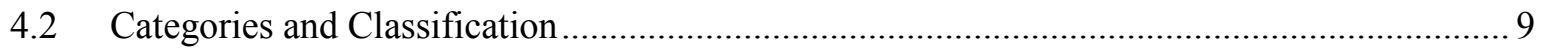

4.2.1 What information does the NEID store about a facility or instrument?.................... 9

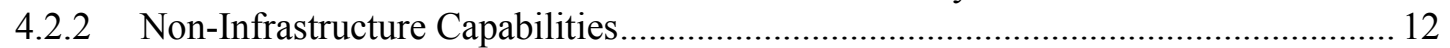

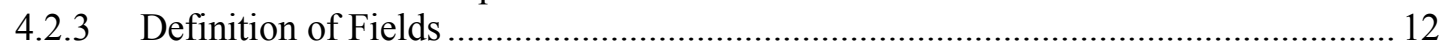

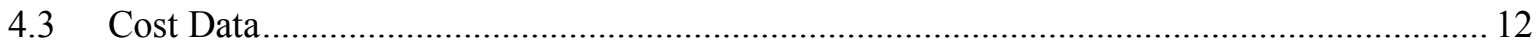

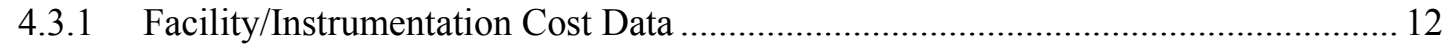

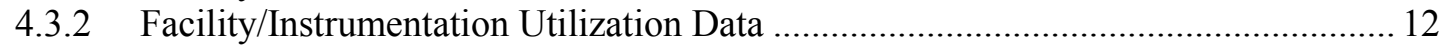

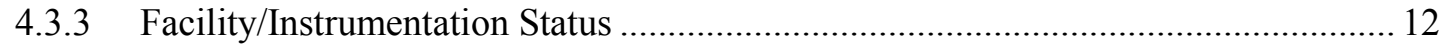

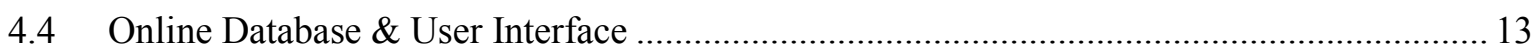

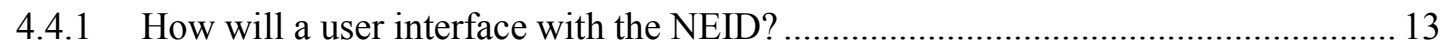

4.4.2 What sort of results will the user get from the NEID? ....................................... 15

4.4.3 How will the NEID be tested before deployment? ................................................ 16

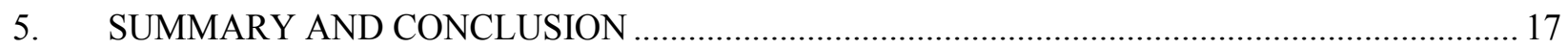

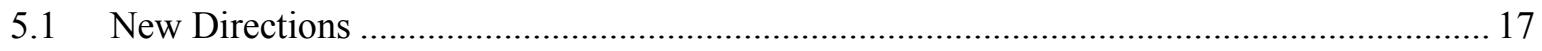

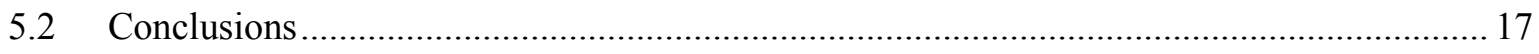

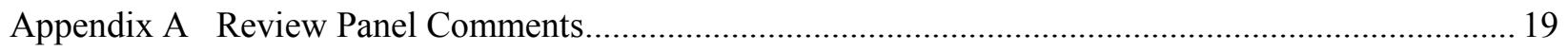

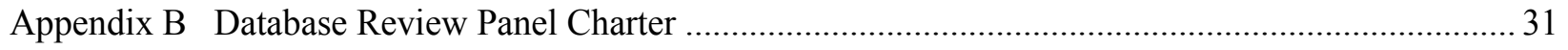




\section{ACRONYMS}

$\begin{array}{ll}\text { ATR } & \text { Advanced Test Reactor } \\ \text { DOE } & \text { Department of Energy } \\ \text { DRP } & \text { Database Review Panel } \\ \text { FIMS } & \text { Facility Information Management System } \\ \text { FY } & \text { fiscal year } \\ \text { GIS } & \text { Geographical Information System } \\ \text { IAEA } & \text { International Atomic Energy Agency } \\ \text { IM } & \text { Information Management } \\ \text { INL } & \text { Idaho National Laboratory } \\ \text { NE } & \text { Nuclear Energy } \\ \text { NEID } & \text { Nuclear Energy Infrastructure Database } \\ \text { NSUF } & \text { Nuclear Science User Facilities } \\ \text { POC } & \text { point of contact } \\ \text { R\&D } & \text { research and development }\end{array}$




\section{Nuclear Energy Infrastructure Database Fitness and Suitability Review}

\section{PURPOSE OF THE NUCLEAR ENERGY-INFRASTRUCTURE MANAGEMENT PROJECT}

In 2014, the Deputy Assistant Secretary for Science and Technology Innovation initiated the Nuclear Energy (NE)-Infrastructure Management Project by tasking the Nuclear Science User Facilities (NSUF), formerly the Advanced Test Reactor National Scientific User Facility, to create a searchable and interactive database of all pertinent NE-supported or related infrastructure. This database will be used for analyses to identify needs, redundancies, efficiencies, distributions, etc., to best understand the utility of NE's infrastructure and inform the content of the infrastructure calls.

Additionally, NSUF was tasked to develop a web-based application to track research and development (R\&D) facilities and associated equipment throughout the NE complex. The system will allow internal authorized users to enter, update, and search facilities and equipment as well as allowing authorized users to run defined reports. There will be one version of the online database (PRIVATE) for internal users, such as Department of Energy (DOE), national laboratory staff and other authorized personnel. There will be another version of the database (PUBLIC) for users and potential users to view the inventory of NE-compatible R\&D capabilities available to them through the NSUF. These may be the same database, with various levels of permissions applied to each category of information.

This new directive is built upon the NSUF mission of providing no-cost access to specialized facilities by:

1. Developing and maintaining a Nuclear Energy Infrastructure Database (NEID) at:
a. National laboratories
b. Universities
c. Industrial R\&D facilities
d. International R\&D facilities

2. Coordinating the Office of Nuclear Energy infrastructure awards
a. University reactor upgrades
b. University general scientific infrastructure
c. Nuclear Energy Enabling Technologies Crosscutting Technology Development
d. NSUF access awards. 


\section{DESCRIPTION OF THE NUCLEAR ENERGY INFRASTRUCTURE DATABASE (NEID)}

The NSUF developed the database by utilizing data and policy direction from a variety of reports from the DOE, the National Research Council, the International Atomic Energy Agency (IAEA), and various other federal and civilian resources. This basis was built upon with specific searches of institution's internet sites and written surveys to U.S. academic institutions.

\subsection{Database Structure}

The data was compiled into a Microsoft Access ${ }^{\mathrm{TM}}$ database format, with one database for R\&D facilities and another for the R\&D instrumentation. That database is being converted to a Structured Query Language database, which will then be accessed through a web portal. The database development activities are being pursued by the Information Management (IM) staff at Idaho National Laboratory (INL). A draft version of the database is available internally at INL at impac.inl.gov. It is intended only for usability testing and idea development.

The NSUF and IM staff will also use Geographical Information System (GIS) technologies to visualize the data in the NEID. This is designed to make the NEID easier to utilize efficiently by all user levels.

\subsection{Database Contents}

The NEID currently contains data on 802 R\&D instruments housed in 377 facilities at 84 institutions in the U.S. and abroad. Because this project has only just started, many of the entries currently lack detail. The NSUF has plans in place to fill in this detail, by use of focused surveys and other tools, over the next year.

The final implementation of the Structured Query Language database will include access to (directly or indirectly) other federal databases such as:

1. Facility Information Management System (FIMS): real estate database

2. Sunflower: property management database tied into equipment acquisitions

3. Nuclear Science and Technology Directorate at INL Availability Database: equipment status.

Other resources, such as IAEA databases, may be accessed and have data entered manually. 


\section{DATABASE REVIEW PANEL}

The Database Review Panel (DRP) was formed to review and provide advice on the development, implementation, and utilization of the NEID. Additionally, the DRP can provide an expert opinion of needed infrastructure for near-, mid-, and long-term future research in support of the NE mission in accordance with established NE direction, such as the NE R\&D Roadmap. Their input can be used as one of many sources used in the gap analysis to be completed in fiscal year (FY) 2015 that will assist in providing recommendations and support for future funding opportunities. The DRP Charter is included as Appendix B to this report.

\subsection{Duties}

The DRP was tasked to provide the following to the NSUF:

1. Review the structure of the database, including:

a. Types of facilities and instruments to be included in the database

b. Types of information to be included about the facilities and instruments in the database

c. Layout and usability of the database.

2. Review the contents of the database, including:

a. Missing facilities or instruments

b. Errors in data entered in the database.

3. Provide an expert opinion of needed infrastructure for future research in support of the NE mission (for utilization as one source in the capability gap analysis)("Needs" Report).

4. Provide preliminary input on possible implementation strategies for future NSUF management of NE-associated R\&D infrastructure.

\subsection{Membership}

The panel is comprised of five members with expertise in NE-associated research. It was intended that they represent the major constituencies associated with NE research: academia, industry, research reactor, national laboratory, and DOE program management. The panel will be chaired by the NSUF Research and Development Infrastructure Lead (Dr. Brenden Heidrich). In their representation of the constituencies listed above, it is anticipated that a portion of the DRP membership will come from the NSUF User's Organization Executive Committee or the Capabilities and Infrastructure Committee. Other members of the DRP, in addition to the chair, will come from DOE and/or other external groups. Table 1 shows the proposed DRP membership for FY 2015. Membership on the DRP is at the discretion of the chair.

Table 1. FY 2015 NSUF NE infrastructure DRP membership.

\begin{tabular}{|l|l|l|}
\hline \multicolumn{1}{|c|}{ Name $^{\text {a }}$} & \multicolumn{1}{c|}{ Institution } & \multicolumn{1}{c|}{ Constituency } \\
\hline Brenden Heidrich & INL & NSUF (Chair) \\
\hline Jason Tokey & DOE-NE Office of Facilities Management & Program Management \\
\hline Dave Senor & Pacific Northwest National Laboratory & National Laboratory \\
\hline Peng Xu & Toshiba-Westinghouse & Industry \\
\hline Lin-wen $\mathrm{Hu}$ & Massachusetts Institute of Technology & University \\
\hline
\end{tabular}

${ }^{\text {a }}$ Peter Hosemann from University of California Berkeley will act as an alternate in the event a member cannot complete their duties. 


\subsection{Deliverables}

The DRP membership will provide input and feedback to the R\&D Infrastructure Lead, who will generate two reports based on the panel's work, as detailed in Table 2.

Table 2. FY 2015 deliverables.

\begin{tabular}{|c|c|}
\hline Report & Completion Date \\
\hline $\begin{array}{l}\text { 1. DRP NE Infrastructure Database Fitness and Suitability Report } \\
\text { - Fitness of the data included in the NEID } \\
\text { - Suitability of the structure of the NEID. }\end{array}$ & March 15, 2015 \\
\hline $\begin{array}{l}\text { 2. DRP NE R\&D Capability Needs Report } \\
\text { DRP member's expert opinions of the infrastructure requirements to } \\
\text { support the near-, mid- and long-term future Nuclear Engineering research. }\end{array}$ & April 30, 2015 \\
\hline
\end{tabular}

\subsection{Proposed Timetable of the DRP for FY 2015}

Table 3 details the proposed timetable of the DRP in FY 2015.

Table 3. FY 2015 timetable.

\begin{tabular}{|l|c|}
\hline \multicolumn{1}{|c|}{ Event or Task $^{\text {a }}$} & Completion Date \\
\hline $\begin{array}{l}\text { Formation of DRP and acceptance of charter and plan by: DOE-NE, NSUF } \\
\text { Director and proposed panel members. }\end{array}$ & January 30, 2015 \\
\hline $\begin{array}{l}\text { Dr. Heidrich presents summary of DRP efforts to the Nuclear Energy } \\
\text { Advisory Committee-Facilities Subcommittee }\end{array}$ & February 19,2015 \\
\hline $\begin{array}{l}\text { Panel members provide their review of the database format and contents to the } \\
\text { chair. Dr. Heidrich generates NEID fitness and suitability report. }\end{array}$ & February 27, 2015 \\
\hline $\begin{array}{l}\text { Dr. Heidrich provides support to Nuclear Energy University Program/Nuclear } \\
\text { Energy Enabling Technology infrastructure application review using database } \\
\text { and other supporting resources, including DRP opinions as appropriate. }\end{array}$ & March 19,2015 \\
\hline $\begin{array}{l}\text { Panel provides expert opinion of R\&D direction and capability needs to the } \\
\text { chair. Dr. Heidrich generates the DRP NE R\&D Capability “Needs" Report. }\end{array}$ & April 30,2015 \\
\hline $\begin{array}{l}\text { Dr. Heidrich presents summary of DRP efforts to the NSUF Scientific Review } \\
\text { Board. }\end{array}$ & June 2,2015 \\
\hline $\begin{array}{l}\text { Dr. Heidrich presents summary of DRP efforts to the NSUF User's } \\
\text { Organization during User's Week. }\end{array}$ & June 22, 2015 \\
\hline
\end{tabular}

${ }^{\mathrm{a}}$ Review of the project by the DOE program office can be performed at any time. 


\section{REVIEW COMMENTS FROM THE NEID DATABASE REVIEW PANEL}

The detailed comments and responses are in Appendix A. This section attempts to group the comments by functional area and provide discussion of the improvements made in response to the panel's input.

\subsection{Data and Data Sources}

\subsubsection{What capabilities will be included in the NEID?}

The NEID is designed to identify and document all of the major capabilities associated with NE research across the DOE complex. This has been expanded to cover similar capabilities at universities and commercial sites, primarily in the U.S., but also international facilities of interest.

Currently, the NEID contains data on 802 R\&D instruments housed in 377 facilities at 84 institutions in the U.S. and abroad. There is still detailed data to be gathered about these capabilities and some additional capabilities to be discovered and added to the NEID, but the vast majority of capabilities are cataloged in the NEID. Figures 1 and 2 show the functional distribution of the facilities and instruments in the NEID. Figure 3 shows the distribution of institutional owners of the R\&D capabilities.

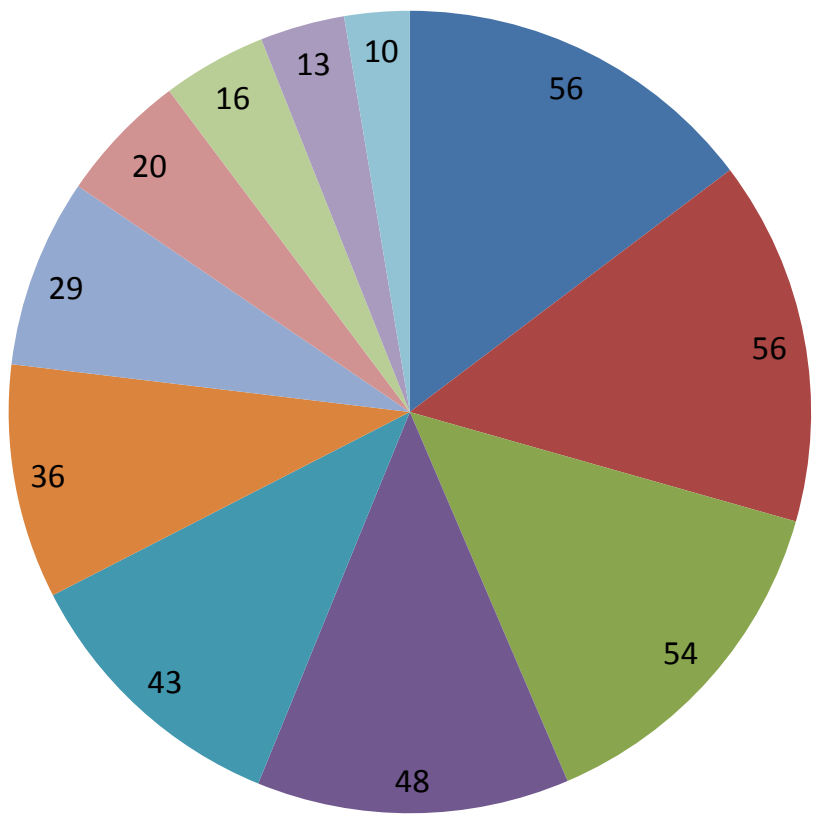

- PIE/Materials Characterization

Reactor Facilities

- Hot Cell Facilities

- Radiochemistry Laboratories

- Thermal-Hydraulic Test Facilities

Special Laboratories

Accelerator Facilities

- Photon Beam/Gamma Facilities

Fuel Development Facilities

Neutron Beam Facilities

- Sample Preparation Facilities

Figure 1. Functional distribution of the 377 facilities in the NEID (February 27, 2015). 


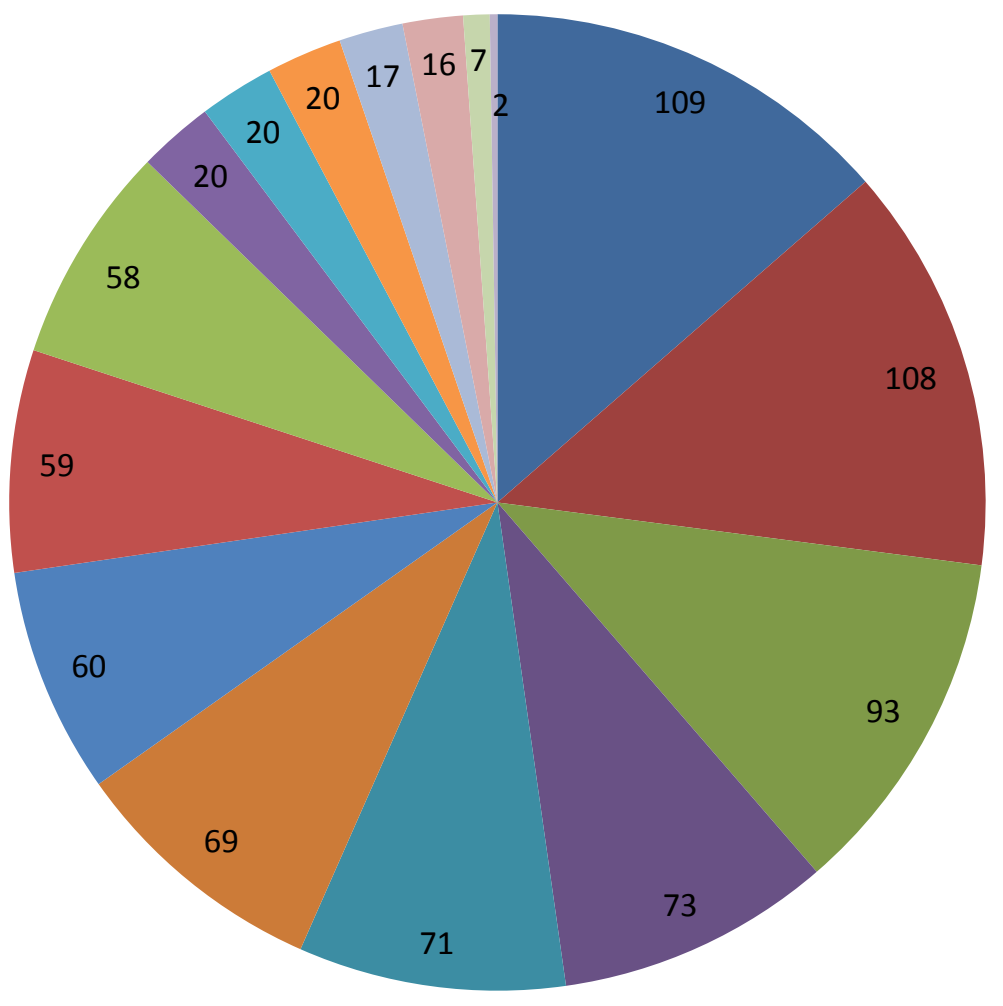

Microscopes and Detectors

- Spectrometry \& Spectroscopy

- Shipping Containers (Casks)

- Mechanical Testing

Neutron Beam Instruments

Thermal Testing

- Containment (Glove Boxes)

- Sample Preparation Gear

Chemical Testing

- Dimensional Examination

Surface Techniques

X-ray Diffraction Instruments

Fuel Fabrication

Radiography

Photon Source Facility Instruments

Electromagnetic Testing

Figure 2. Functional distribution of the 802 instruments in the NEID (February 27, 2015).

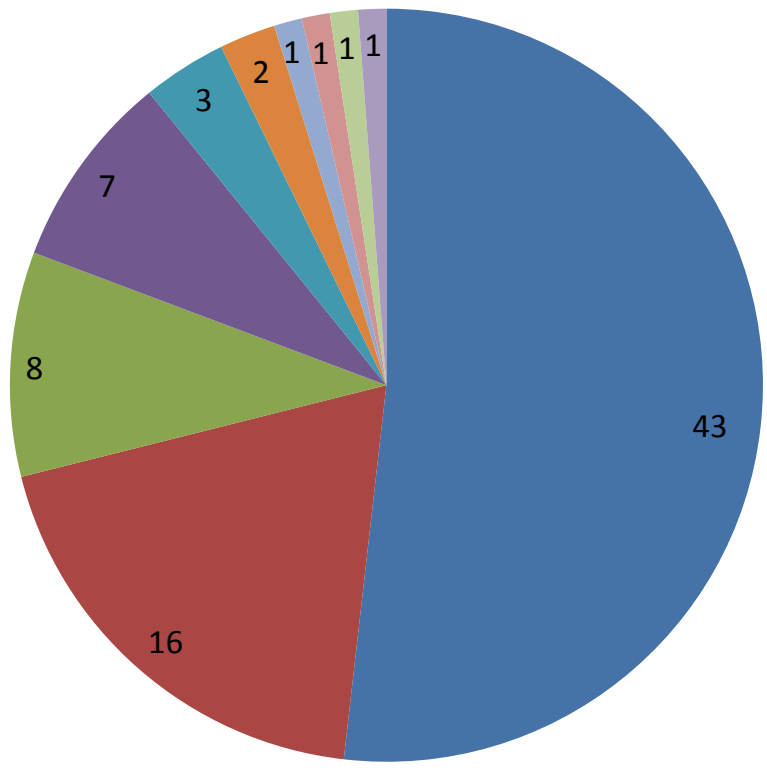

- US University

Department of Energy

US Industry

- Foreign Government

Department of Defense

Foreign Industry

Department of Commerce

Department of Interior

State of Rhode Island

Foreign University

Figure 3. Institutional affiliations for the NEID capabilities (February 27, 2015). 


\subsubsection{How will the data in the NEID be kept current?}

The NEID will be maintained through a tiered approach. NSUF staff will work with INL IM and the various facilities to gather and input the data in an efficient manner.

1. Data for DOE-complex facilities (real estate) are maintained through the FIMS. This database contains information about the condition of the facility as well as its fitness for meeting mission needs. The fields of interest are shown in Table 4. The FIMS database will be queried periodically and the data fed into the NEID.

2. Acquisition data for DOE-complex instrumentation are maintained through the Sunflower database system. The NEID will be setup to query the INL implementation of the Sunflower system. Similar systems are in use at other DOE-complex laboratories although their implementation may differ slightly from INL. The other laboratories will be queried for input periodically. Ideally, they would format their data to match the NEID format. The data translation may have to be handled by NSUF/INL. Sunflower data can be filtered by various criteria, including initial cost of the equipment and federal supply codes.

3. NSUF partner facilities will be polled periodically for updates to their facility and instrumentation entries. This can be accomplished either manually or by giving them access to the NEID so they can edit their own entries. Their participation in this effort will be part of the partner agreement between NSUF and the partnering institution.

4. Other facilities in the NEID will be polled periodically for updates to their facility and instrumentation entries. Their participation in this effort is voluntary and will likely be less than complete.

To facilitate this effort, the point of contact address and telephone number will be added to the facility and instrumentation entries in addition to their name and e-mail address.

Table 4. FIMS Data for the NEID.

\begin{tabular}{|l|l|}
\hline Property Name & $\begin{array}{l}\text { Laboratory Operations Board Overall } \\
\text { Asset Condition }\end{array}$ \\
\hline Property Type & $\begin{array}{l}\text { Laboratory Operations Board } \\
\text { Condition Notes }\end{array}$ \\
\hline Ownership & Core Capability - Primary \\
\hline Mission Dependency & Core Capability - Secondary \\
\hline Status & Core Capability - Tertiary \\
\hline Hazard Category & Asset \% Utilized \\
\hline Elevated Security & Asset Utilization Level \\
\hline Repair Needs & Utilization Notes \\
\hline Deferred Maintenance & $\begin{array}{l}\text { Laboratory Operations Board } \\
\text { Utilization Space Type \% Utilized }\end{array}$ \\
\hline Summary Condition & $\begin{array}{l}\text { Laboratory Operations Board } \\
\text { Utilization Space Type Util. Level }\end{array}$ \\
\hline
\end{tabular}




\subsubsection{What sources were used to initially populate the NEID?}

Over 50 references were used in the first 6 months of the project. Twenty-four sources or sets of sources were gleaned to provide the information that formed the NEID. A listing of these is shown here in Table 5 .

Table 5. Infrastructure references for the NEID.

\begin{tabular}{|l|l|}
\hline Reference & Date \\
\hline $\begin{array}{l}\text { 1. IAEA Databases Research \& Test Facilities Database, Research and } \\
\text { Test Reactor Database \& Beamline Database) }\end{array}$ & $\leq 2015$ \\
\hline 2. Facility Site (web page) & 2015 \\
\hline 3. Facility NSUF User's Guide & 2014 \\
\hline 4. Facility Fact Sheets/Annual Reports/etc. & 2014 \\
\hline 5. www.lightsources.org (web page) & 2015 \\
\hline 6. Hot Cell Strategy Report & 2006 \\
\hline $\begin{array}{l}\text { 7. Alternatives to Academic and Professional International Evaluations } \\
\text { report \& raw data }\end{array}$ & 2012 \\
\hline 8. DOE Facilities Inventory Draft (June 16, 2014) & 2014 \\
\hline 9. Required Assets for a NE Applied R\&D Program & 2009 \\
\hline $\begin{array}{l}\text { 10. Nuclear Energy University Program Research Reactor Infrastructure } \\
\text { Program Annual Reports }\end{array}$ & $2012-3$ \\
\hline 11. INL Ten-Year Site Plans & $2012-4$ \\
\hline 12. DOE-Office of Science User Facilities Ten-Year Plan & 2013 \\
\hline 13. DOE-NE Infrastructure FOA Awards & 2015 \\
\hline 14. INL Portfolio Integration \& Prioritization Tool & 2012 \\
\hline 15. INL Nuclear Science and Technology Directorate Inventory System & 2015 \\
\hline $\begin{array}{l}\text { 16. Nuclear Regulatory Commission Test, Research, and Training } \\
\text { Reactor Licensing Presentation (ML14226A953) }\end{array}$ & 2014 \\
\hline $\begin{array}{l}\text { 17. Nuclear Regulatory Commission Test, Research, and Training } \\
\text { Reactor Licensing Presentation (ML12269A373) }\end{array}$ & 2012 \\
\hline $\begin{array}{l}\text { 18. Nuclear Science and Engineering Education Sourcebook (American } \\
\text { Nuclear Society/DOE) }\end{array}$ & $2013-4$ \\
\hline 19. NRC.GOV (web page) & 2015 \\
\hline $\begin{array}{l}\text { 20. Nuclear Regulatory Commission Compliance Certificate } \\
\text { radioactive materials packaging) }\end{array}$ & 2015 \\
\hline 21. Sunflower Property Management Database & 2015 \\
\hline 22. Advanced Fuel Cycle Facility Existing Facilities Data Report & 2008 \\
\hline 23. Facilities for the Future of NE Research & 2009 \\
\hline 24. INL Facility Planning Portal & 2015 \\
\hline 99. Personal/Phone/E-mail Contact & 2015 \\
\hline
\end{tabular}

An additional reference, U.S. DOE, "Directory of Operating Research, Training, and Test Reactors in the United States of America," Fourth Edition, 1997, will be researched as a possible addition to the NEID. 


\subsection{Categories and Classification}

\subsubsection{What information does the NEID store about a facility or instrument?}

The NEID structure will change slightly as a result of the initial review by the DRP as well as several uses of the database to assist NSUF users. Originally, the NEID was arranged into two individual databases: one for R\&D facilities and one for instruments. These were sorted by purpose. The major capabilities are shown in Table 6.

Table 6. Types of facilities and instruments in initial NEID design.

\begin{tabular}{l|l}
\hline Facility Categories & Instrumentation Categories \\
\hline Accelerator Facilities & Chemical Testing \\
Fuel Development Facilities & Containment (Glove Boxes) \\
Hot Cell Facilities & Dimensional Examination \\
Neutron Beam Facilities & Electromagnetic Testing \\
Photon Beam/Gamma Facilities & Fuel Fabrication \\
Post-irradiation & \\
Examination/Materials & Ion Beam Instruments \\
Characterization & \\
Radiochemistry Laboratories & Mechanical Testing \\
Reactor Facilities & Microscopes and Detectors \\
Sample Preparation Facilities & Neutron Beam Instruments \\
Special Laboratories & Photon Source Facility Instruments \\
Thermal-Hydraulic Test Facilities & Radiography \\
& Sample Preparation Gear \\
& Shipping Containers (Casks) \\
& Spectrometry \& Spectroscopy \\
& Surface Techniques \\
& Thermal Testing \\
X-ray Diffraction Instruments
\end{tabular}

Roughly 50 fields of information were gathered for both types as shown in Table 7.

The fields were chosen to ease searching by potential users and so that each NEID entry could stand on its own. Based on DRP input and actual utilization of the NEID, the database design has been updated so that institution, facility, and instrument entries contain the information important to each one. Instruments are linked in the database to their home facility, which is linked to its home institution. As before, specific sets of fields are available to add specialized information about different types of facilities and instruments. The main fields for the updated NEID are shown in Table 8.

The new fields are highlighted.

- The light-green fields have been added to support GIS mapping integration with the NEID.

- The light-blue fields have been added to support multiple capabilities for the facilities and instruments.

- The light-violet fields are data from the FIMS database.

- The light-red fields are from DRP comments. 
Table 7. Information fields for facilities and instruments in initial NEID design.

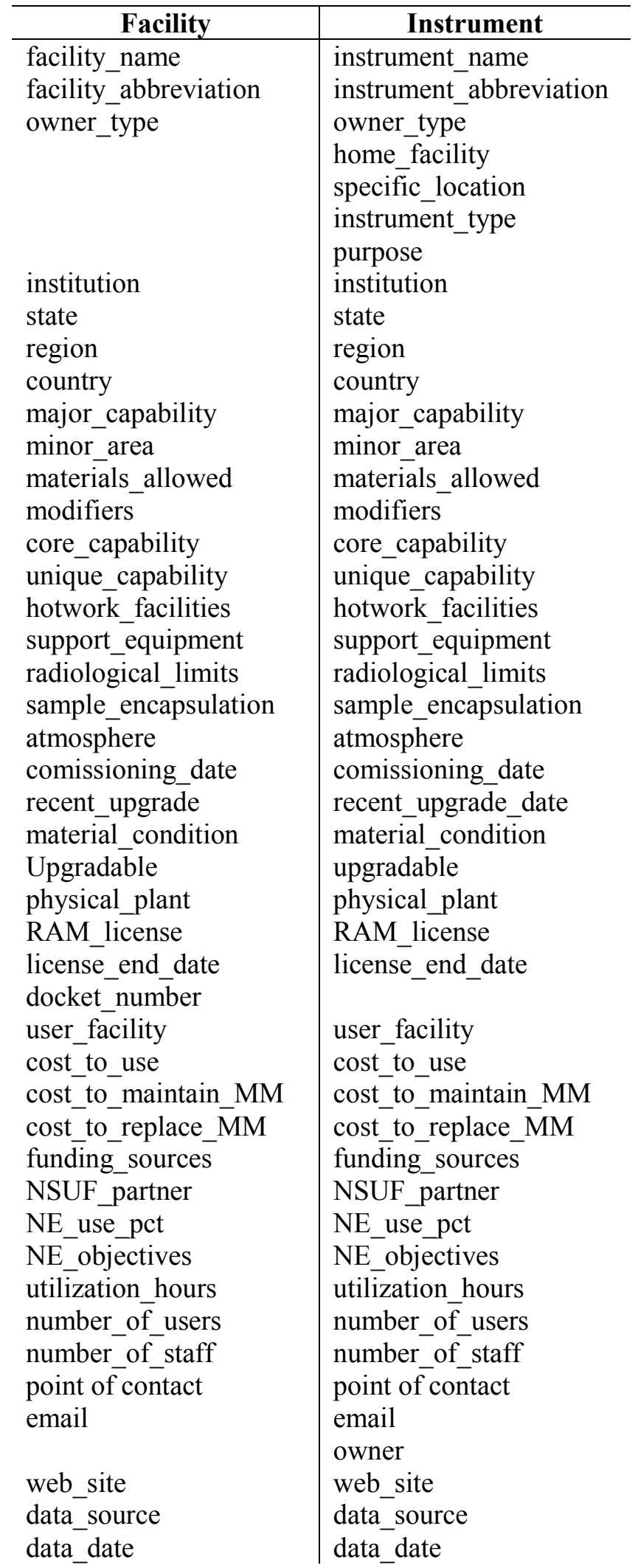


Table 8. Information fields for facilities and instruments in the updated NEID design.

\begin{tabular}{|c|c|c|}
\hline Institution & Facility & Instrument \\
\hline Institution name & Facility Name & Instrument Name \\
\hline Owner Type & Abbreviation & Instrument Abbreviation \\
\hline State & Institution & Home Facility \\
\hline Region & Core Capability & Core capability \\
\hline Country & Unique Capability & Unique capability \\
\hline \multirow[t]{8}{*}{ Map Coordinates } & Hot Work Facilities & Radiological Limits \\
\hline & Materials Allowed & Materials Allowed \\
\hline & Support Equipment & Support Equipment \\
\hline & Building & Building \\
\hline & Map Coordinates & Map Coordinates \\
\hline & $\begin{array}{l}\text { Type of Facility (hot cells, post- } \\
\text { irradiation examination, etc.)-1 }\end{array}$ & Major Capability-1 \\
\hline & $\begin{array}{l}\text { Type of Facility (hot cells, post- } \\
\text { irradiation examination, etc.)-2 }\end{array}$ & Minor Area-1 \\
\hline & $\begin{array}{l}\text { Type of Facility (hot cells, post- } \\
\text { irradiation examination, etc.)-3 }\end{array}$ & Major Capability-2 \\
\hline FIMS (Facility) Data & $\begin{array}{l}\text { Type of Facility (hot cells, post- } \\
\text { irradiation examination, etc.)-4 } \\
\end{array}$ & Minor Area-2 \\
\hline Property Type & Regulating Agency & Major Capability-3 \\
\hline Ownership & License end date & Minor Area-3 \\
\hline Mission Dependency & Recent Major Upgrade & Modifiers \\
\hline Status & Material Condition & Floor \\
\hline Hazard Category & Mission Upgradable? & Room \\
\hline Elevated Security & Supporting Physical Plant & Sample Encapsulation \\
\hline Summary Condition & & Atmosphere/environment \\
\hline Overall Asset Condition & No. of staff & Number of Items \\
\hline Condition Notes & User Facility or Contract? & Cost to Use \\
\hline Core Capability - Primary & NSUF Partner? & Cost to Maintain \\
\hline Core Capability - Secondary & Funding Sources & Cost to Replace \\
\hline Core Capability - Tertiary & DOE-NE Use [\%] & DOE-NE Use [\%] \\
\hline Asset \% Utilized & NE Objectives $[1,2,3,4]$ & NE Objectives $[1,2,3,4]$ \\
\hline Asset Utilization Level & No. of users & Utilization [\%] \\
\hline Utilization Notes & Commissioning Date & Commissioning Date \\
\hline Space Type \% Utilized & Contact information & Contact information \\
\hline Space Type Util. Level & E-mail Address & E-mail Address \\
\hline & Contact Address & Contact Address \\
\hline Instrument Specific Data & Contact Telephone & Contact Telephone \\
\hline Manufacturer & Web Site & Web Site \\
\hline Model & Source(s) of Data & Source(s) of Data \\
\hline $\begin{array}{l}\text { This will have several } \\
\text { different choices here for } \\
\text { reactors, microscopes, etc. }\end{array}$ & Date of Data & Date of Data \\
\hline
\end{tabular}




\subsubsection{Non-Infrastructure Capabilities}

Another concern of the panel was the ability to capture capabilities that did not involve an instrument, such as experimental design or neutronics analysis. While this has not been ultimately decided, a significant capability of this sort, such as the Test Train Assembly Facility at INL, could be added as a facility. Smaller capabilities can be added as an instrument, if there is a facility to which they can be related. This is an open item.

\subsubsection{Definition of Fields}

There was confusion about the type and format of data that is assigned to a particular field. The IM staff can attach a set of definitions to the fields in the NEID that can be accessed either by a separate link on the web page or on "mouse-over" when using the web page. The definitions will need to be written, but they can be attached to the NEID at any time.

\subsection{Cost Data}

\subsubsection{Facility/Instrumentation Cost Data}

The NEID currently stores cost related data for three categories:

1. Cost to use

2. Cost to maintain

3. Cost to replace.

This data was obtained or will be obtained from a variety of sources, mostly self-reported. FIMS (repair needs and deferred maintenance) and Sunflower (original purchase price) will have some of this data for DOE-complex facilities. Facilities that follow the user facility model will often have stated price lists for instruments. In many cases, this data will be difficult to obtain.

\subsubsection{Facility/Instrumentation Utilization Data}

The NEID stores utilization data for facilities and instruments. Like cost data, this is largely self-reported. FIMS supplies utilization data for DOE-complex facilities. The INL Ten-year Site Plan supplies similar data, as do other similar documents for other facilities. University research reactors supply this data to the Research Reactor Infrastructure program (DOE) and the IAEA database.

Instrument data can be expressed in hours/year or in percentage of time utilized. It must be considered what the datum is for these cases. It can either be the total calendar time or some value less than that, based on available time. The definition of "utilization" will also be prescribed as the time available for use by a researcher, to differentiate it from maintenance activities.

\subsubsection{Facility/Instrumentation Status}

The "status" of a facility or a piece of instrumentation will let the NEID user know if the capability is operational, in standby or pending decommissioning. This data is available in FIMS for DOE-complex facilities, but it is much harder to ascertain for instruments and non-DOE-complex facilties. The best direction is likely to be facility visits or periodic queries of the equipment/facility owner. 


\subsection{Online Database \& User Interface}

The NSUF envisions three types of users for the NEID:

1. Administrators and Sub-admins. Editors of the database (NSUF staff) and partners who can add and update data entries, but not delete them.

2. Programmatic Users. Federal or laboratory staff who will search the internal or private database for information about NE R\&D capabilities either to help inform funding decisions or to support their own research goals.

3. External Users. Academic or commercial researchers who will search the external or public version of the database to support their own research goals.

One important goal for the next few months is the collection of the types of queries and reports needed by the users of the NEID. This will help guide the development of the website and the interface to increase usability for all types of users.

\subsubsection{How will a user interface with the NEID?}

The typical interaction between a user and the NEID will be through the web portal. Currently, the NEID is available at impac.inl.gov, which is accessible only through the INL network. This is intended for development and testing only, although it has been used to answer questions in a few initial cases.

In the future, NEID will be accessed through the Nuclear Energy University Program web page. This would allow the NEID to use the same login information and user profiles it currently employs. Since external users would visit the Nuclear Energy University Program page for proposals already, this is a logical location for the NEID. Security will be maintained by user access levels for each field in the NEID. Internal users would be able to see more (or all) of the NEID data, while external users would be limited to fewer fields.

The current version of the NEID web page is shown here.

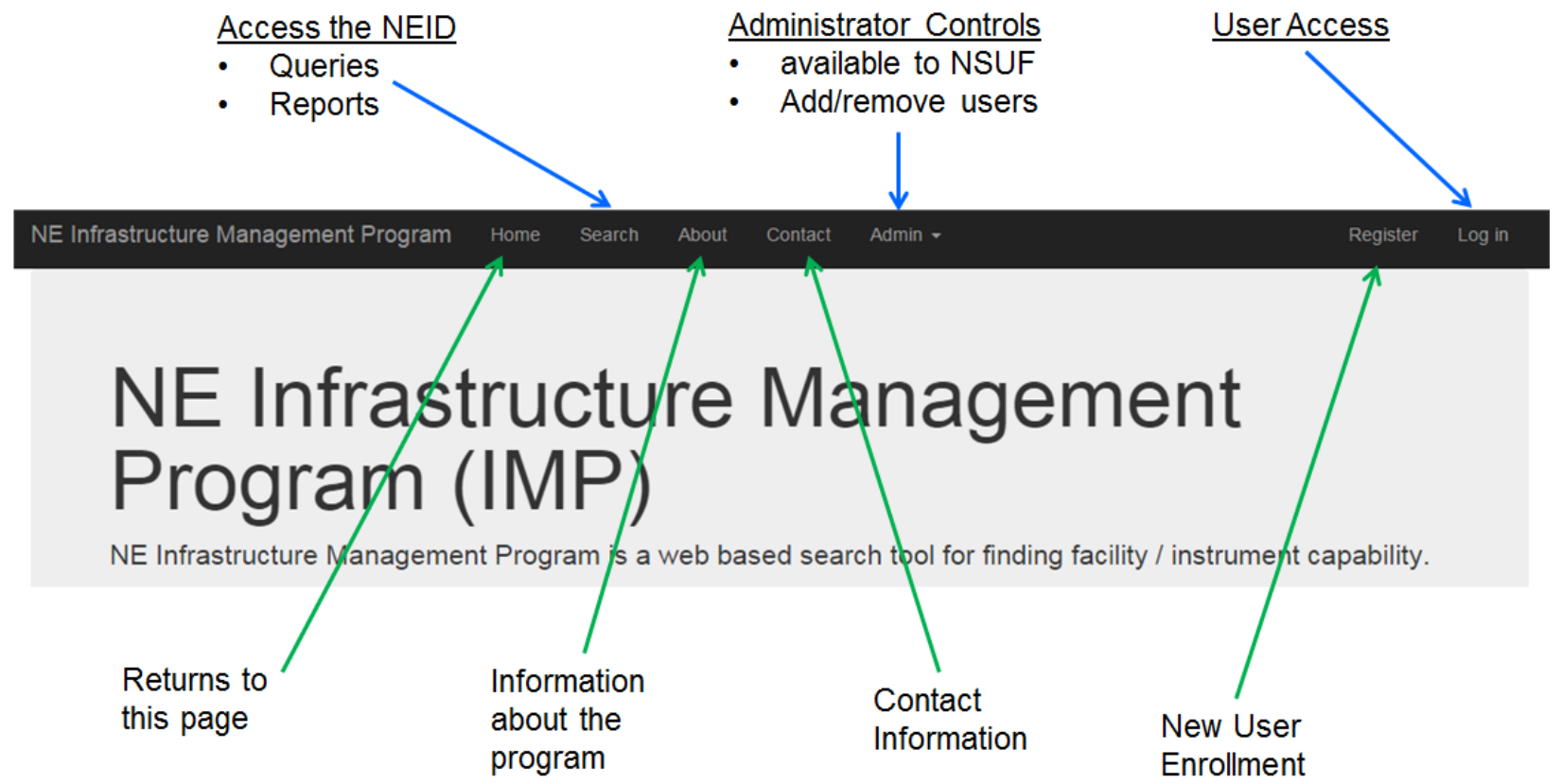

Figure 4. NEID draft web page at impac.inl.gov.

The NEID is accessed through the search tab. The main interface is the grid view. 


\section{Search}

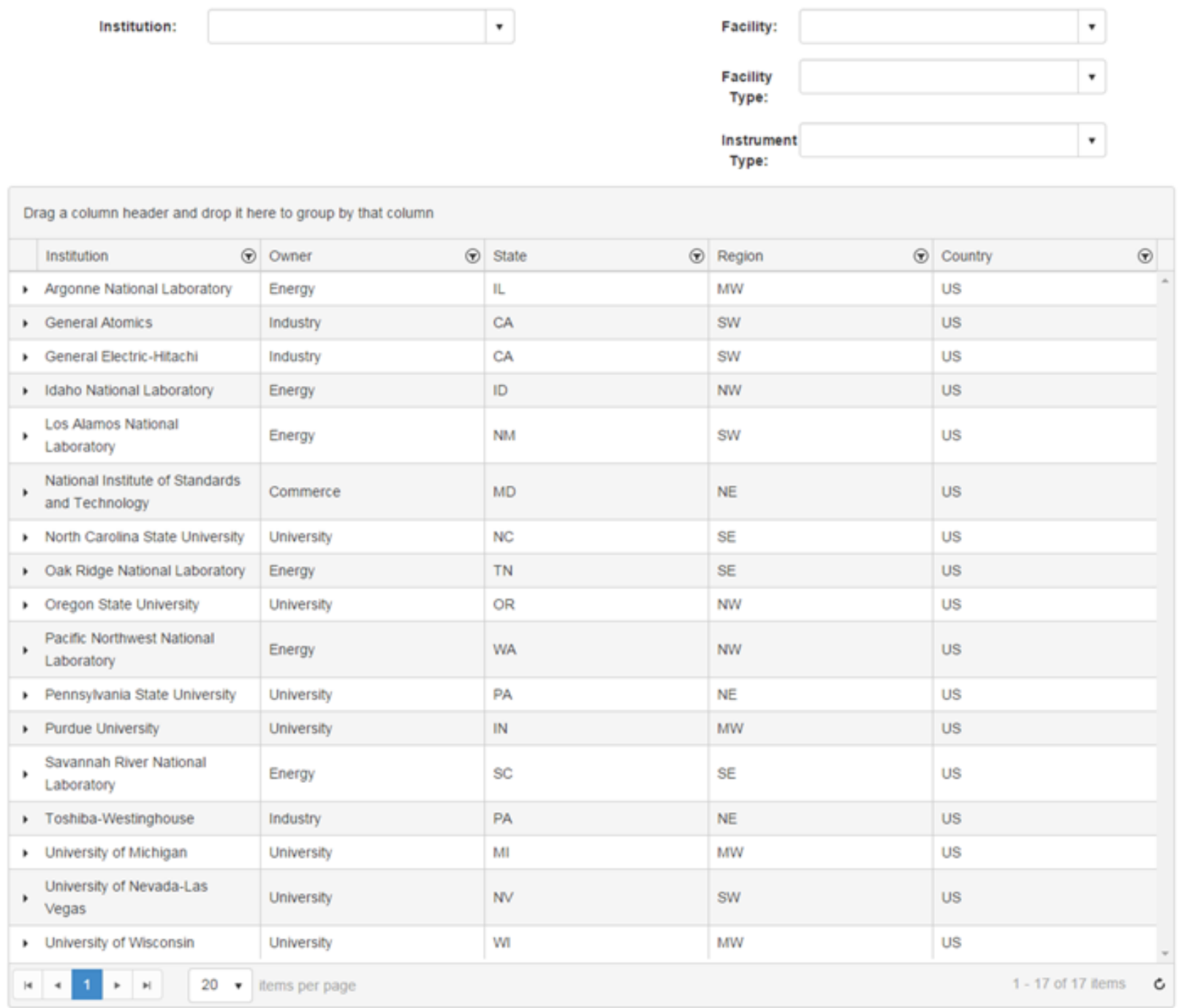

Figure 5. Draft NEID web page. Grid view of database search page.

All facilities and instruments are shown in this view. Sorts and filters are available in each column, similar to a spreadsheet. A user can filter the whole page using the four drop-down lists above the table. The whole table can be sorted by dragging a column header to the top. The columns listed here are only temporary placeholders; they can be changed to any of the fields in the NEID. 


\subsubsection{What sort of results will the user get from the NEID?}

There are no direct queries or reports set up in the online version of the database yet. In the future, we envision four types of results.

1. Grid View Data. Most users would merely access the NEID web page and use the grid view and the associated tools to find the information that they need. This is the simplest form of interaction.

2. Pre-built Queries and Reports. More advanced users would access the NEID web page and then select a question or "query" from a drop-down list of pre-built choices. Figure 6 shows some potential examples.

List all of the
\begin{tabular}{|c|} 
Instruments (1) \\
and
\end{tabular}

Instruments (2)

List all of the

Facilities

List all of the

Facilities

$$
\text { available in }
$$$$
\text { State or Region }
$$

\begin{tabular}{l} 
that support \\
NE mission (1-4) \\
that include \\
\hline Instruments (1) \\
and \\
\hline Instruments (2)
\end{tabular}

that can work with:

Radioactive
Material limit

that are older than:

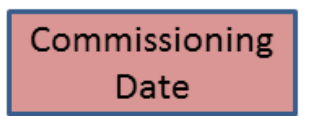

that are NSUF partners.

\section{NSUF partner}

Figure 6. Examples of possible pre-built query functions.

3. Custom Queries. These are the typical database queries. An even more advanced user would be able to query all of the database fields in a variety of orders and combinations. A simple example is shown here. The user is interested in a listing of government-owned research and test reactors with power levels above $1 \mathrm{MW}$. This is the most powerful tool that would be available to the user, but it is also the most difficult to use. The expectation is that this would require training and would be limited to a small group of (likely internal) users. 


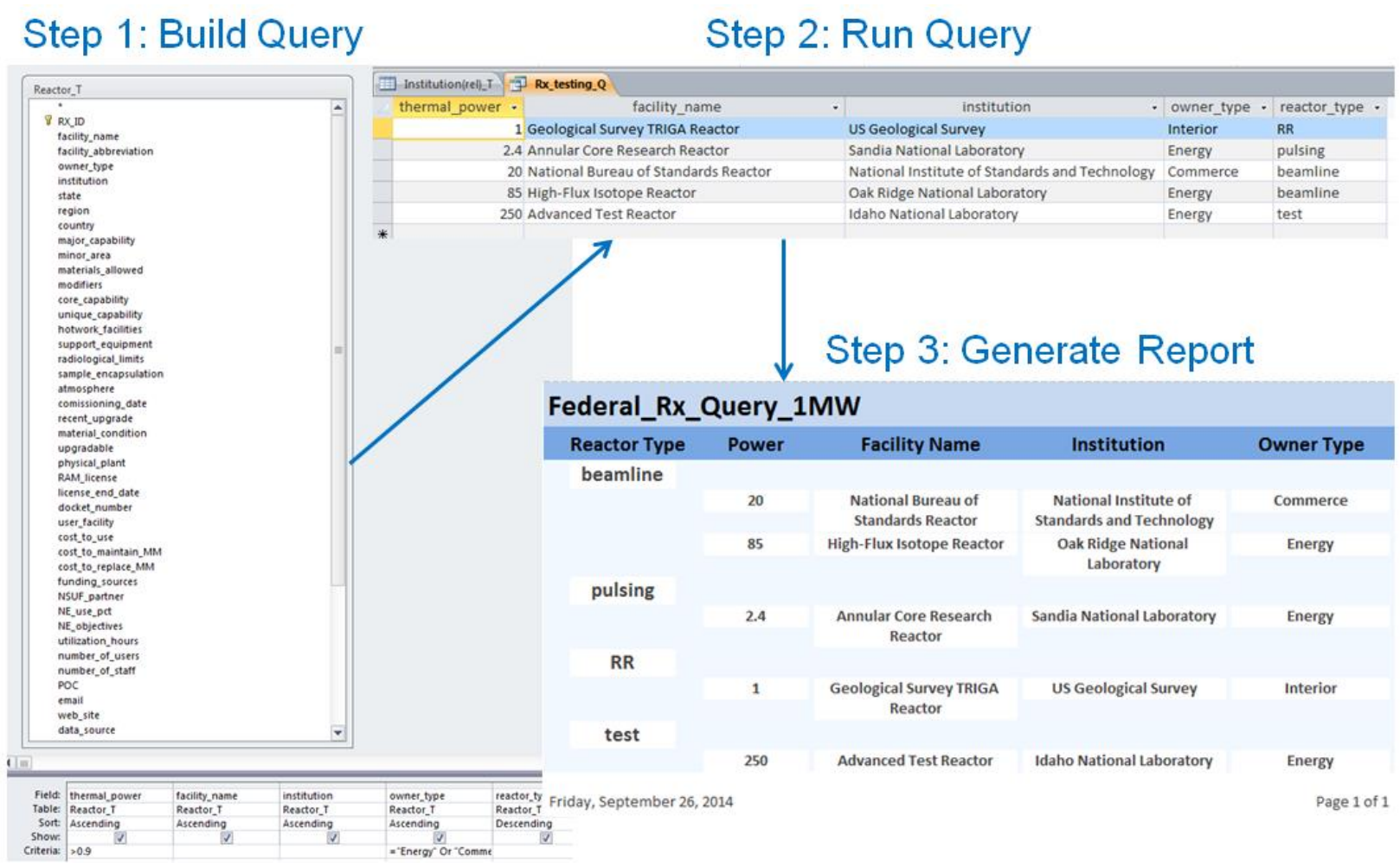

Figure 7. Example of custom query process.

4. GIS Mapping. This would be integrated into the three types of queries to display data visually. While this will aid interpretation of the data, it is not vital to the success of the project, so it will be implemented as schedule and funding allow. It can be added at a later date to the existing NEID. There is a wide variety of GIS examples available on the internet. INL uses a system called iMap, but there are many others in the federal government. The final form of the GIS implementation for the NEID is not set.

\subsubsection{How will the NEID be tested before deployment?}

The NEID web portal will be tested by NSUF and IM staff during development. It will be utilized as possible for all inquiries to the NEID. NSUF will endeavor to make the site available to DRP members for testing before deployment. The development of a wide variety of use cases will help to design the interface even without widespread testing by external users. 


\section{SUMMARY AND CONCLUSION \\ 5.1 New Directions}

As a result of the DRP comments and NSUF efforts since the beginning of the project, the NSUF has elected to apply several improvements and changes to the NEID going forward. The goal of the NEID project is to provide a valuable and usable capability and infrastructure database for NE R\&D capabilities. To this end, input from all possible users is welcomed. Fine-tuning the direction and interface of the database is most efficiently performed during development.

\subsection{Conclusions}

The NEID Review Panel concludes that the NSUF has succeeded in creating a capability and infrastructure database that identifies and documents the major NE R\&D capabilities across the DOE complex, academic institutions, and industry.

The effort to maintain and expand the database will be ongoing. Detailed information on many facilities must be gathered from associated institutions added to complete the database. The data must be validated and kept current to capture facility and instrumentation status as well as to cover new acquisitions and retirements.

The review panel will continue to work on NEID-related matters, including:

- NEID web portal design and user interface

- The development of use cases to support built-in queries and reports

- NE R\&D infrastructure requirements to support the near-, mid-, and long-term future Nuclear Engineering research. 
Appendix A

\section{Review Panel Comments}




\section{Appendix A}

\section{Review Panel Comments}

These comments are only edited for format and arranged into functional groups. They stay as true as possible to the original comments. There were additional notes from the panel concerning database entries that were either missing or in error. Those have been fixed in the Nuclear Energy Infrastructure Database (NEID) and are not shown here, although they are archived. The actual comments and responses are archived with the Nuclear Science User Facilities (NSUF).

The panel member's question or comment is shown in black text. The DRP Chair's response is shown in blue text.

\section{Data and Data Sources}

- Keeping such a comprehensive database up-to-date will be almost as big an undertaking as compiling it in the first place. Have you given thought to how you will keep it current?

- If the data are outdated, they may create more frustration than anything else when users find out the capability they're most interested in is no longer available.

- This is a difficult task. We have to think about how to get our database institutions to keep us informed. At Idaho National Laboratory (INL), the Nuclear Science and Technology Directorate maintains an availability database, but I don't know about elsewhere.

- Similarly, you wouldn't want users to miss out on new equipment that has been recently added to a facility.

- I will be tapping into the Sunflower asset management database. I am told that this is used complex-wide for archiving new purchases. It can be searched by many factors, including cost and federal supply code. Federal Supply Code 66 is "laboratory equipment." This covers a lot of what we are interested in, but things still slip through the cracks. I will work with the appropriate staff here to sharpen that tool.

- I expect to get the best quality information from the national laboratories and other federal facilities. Industry and universities form a different problem. Some are very good, and some are not. Even the labs vary widely in what information is easily available. Once I can get a back-channel into their systems, it will get easier.

- I will need some additional staff over the next year. Even at this point, there is a lot of work that needs to be done to fill in the detail for the database and perform quality and consistency checks on the current data. I have switched into gap analysis mode, where I will be for the rest of the FY. I am adding new data as it comes up naturally, but it is not as concerted of an effort as before.

- We should set up a method (surveys) to get periodic updates from facilities like universities that are not in the federal system. I can query those databases directly.

- From my initial review, I think that the information for the smaller pieces of equipment like the "Neutron_other," "neutron_diff," "Microscope," and "Mechanical" Excel file tabs provide some of the most detailed and descriptive information. It may be that it is just harder to classify the more advanced systems like reactors in this format.

- A lot of the instruments that you are describing had very detailed web pages or user guides. Many other instruments/facilities were lacking. If we want to have this level of detail in the NEID, then we need to apply the resources to achieve that end. It is certainly reasonable to do this. We do 
also have to have a review plan to update the information. I will have that for INL equipment and facilities and possibly other Department of Energy (DOE)-complex sites. Industry and academia are more labor-intensive.

- Was the initial content compiled exclusively from the list of references included in one of the spreadsheets, or did you request input from the various facilities?

- Most of the initial content came from the references, including facility web sites. I did send out a survey to $\sim 75$ universities asking about rad work in materials characterization facilities. Those that said yes were included. I have a survey in draft to ask for detailed information from every facility in the database. It is going through review.

- What is the plan to fill in these empty cells, namely the missing information?

- We are planning to handle the missing data by sending detailed surveys, based on the database fields, to the facilities in the database. I have contact information for most facilities.

- NSUF is also making visits to the NSUF partner facilities over the next 2 months.

- We are also going to get facility data directly from the Facility Information Management System (FIMS) (http://energy.gov/lm/services/property-management/facilities-information-managementsystem-fims). This data was recently updated as part of the DOE Laboratory Operations Board review.

- What is the plan for database maintenance?

- Since one of the reviews is that the amount of maintenance work could be substantial, how can we make it more efficient?

- My plan is to send out a spreadsheet with the facility entry (and instrumentation entries) to each point of contact (POC) annually. I expect to get good response from the labs and NSUF partners. Other institutions will be less likely to comply.

- We will automatically poll the FIMS database frequently (weekly/monthly). Those data will go directly into the NEID for existing facilities.

- We will automatically poll the Sunflower database frequently. We will be able to see (as much as organizations allow) new acquisitions at DOE complex sites.

- Can we ask each POC to report any update?

- Once again, I expect to get good response from the labs and NSUF partners.

- Can we generate automated emails to POC to remind them to update their capabilities and facilities?

- The issue with anyone not directly involved with Nuclear Energy (NE)/NSUF is that they don't have any incentive to help us. The rest of the facilities should be okay.

- Some type of automation is a good idea.

- Can we do anything to make the process simpler and less time consuming for POC to update?

- We can give them access to the online database. They could edit their own entries. It is as easy as filling out a web site form.

- They could read and write, but not delete. I discussed this with the programmers this week. Even if they do try to delete, the system backs up all changes for a long time. 
- For all the POCs, I suggest we include their contact number, address, and their titles in their organization.

- Great idea. I will add that to the programmer's directions.

- The ion beam page should be removed from the instrument spreadsheet.

- There will eventually be instruments on that page. I did not add any to the NEID at this point. It is only a placeholder for now.

- For the sample preparation page, I think University of Wisconsin-Madison and Westinghouse also have capabilities.

- Thank you for the information. I will make sure to inquire and add their capabilities.

- DOE published a directory of operating research, training, and test reactors in the U.S. in 1997 (4th edition). This directory focuses more on reactor operation characteristics than utilization. It would be a valuable resource to include in NEID.

- I will look for this reference. I did use the most recent International Atomic Energy Agency Research and Test Reactor database (http://nucleus.iaea.org/RRDB/RR/ReactorSearch.aspx?rf=1)

- Massachusetts Institute of Technology Reactor, Missouri University Research Reactor and some other research reactors also have neutron beam ports that should be listed in "Neutron_beam" as the PULSTAR and National Bureau of Standards Reactor facilities.

- That is definitely part of the development process. Some categories only have a few entries because I added them as I came across the capability. There are many places to improve. Please let me know as you come across them.

- This type of work, maintaining, growing and validating the NEID, is going to be a point of discussion in the future. I was able to get it so far in the first 6 months. I am looking to add a staff member to take over the maintenance while I focus on the analysis. That will likely happen next FY. Until then, it will move slowly.

- Some facilities listed under post-irradiation examination do not appear to have rad license to receive radioactive materials, such as the California Institute of Technology and University of California, Berkeley facilities. Should these be under the "instrumentation" category?

- I may have been overzealous in adding some of these facilities. In this case, we have a partner at the University of California, Berkeley, Peter Hosemann, who can do some work with radioactive materials. I got a "maybe" from the California Institute of Technology when I inquired about their facilities late last year. I intend to follow up on my initial university survey. There are a few that are interested in expanding into this area.

- More than half of the website links do not work, so they should be fixed.

- As far as I can tell, the web sites are correct addresses.

- I don't know why some of them link from the spreadsheet and why some don't and have to be pasted into a web browser. They may be missing their hyperlink tag. 


\section{Categories and Classification}

- The categories seem pretty comprehensive, but one that I didn't really see would be a "status" category. There are pieces of equipment that exist that in principle are available, but in practice need some sort of maintenance or upgrade before they're really available.

- It would be useful to know when perusing the database whether a piece of equipment is being used on a daily basis or if it's in some sort of mothballed condition.

- Good point. I found a deuterium-tritium neutron generator at the Hot Fuel Examination Facility/Neutron Radiography Reactor that is ready for the trash heap, but there was no indication online that this was not operational.

- If the latter, it would be useful to know what it would take to make it truly usable.

- If the capability is unique enough, a modest investment might be worthwhile to provide data that isn't readily available elsewhere.

- This reminds me of the facility reviews done in support of the NE Roadmap (2010). I am also working with the FIMS database people now. The secretary reformed the Laboratory Operations Board (for a few reasons), and they have been looking at facility conditions and applicability to the NE missions. At the facility-level, I should be able to get those data. As far as instruments go, I think that it would be case-by-case for refurbishment and refit. Intermediate Voltage Electron Microscope is an example that is coming up.

- I am willing to rethink many of the categories in the database. We put the framework together quickly last summer so we had something to use. I appreciate committee input on what we really need to make this useful.

- Is there a category to indicate multiple units of a given instrument? An example that came to mind is gamma spectrometers.

- As an example, at Pacific Northwest National Laboratory we have many gamma spec systems that are all virtually identical. Some indication of capacity would be useful.

- A related issue is some indication of capacity available to the user facility, but this is probably a more difficult thing to capture in a database.

- Unless the instruments are truly fungible, like gamma spec systems in a counting lab, we are better off with individual entries. For a set of eight counting systems in a lab, we should probably have one entry with a field for number of systems.

- Some instruments cross capabilities. An atomic force microscope can be considered a microscope but is also capable of measuring mechanical properties on small dimensional scales.

- When a user searches the database and looks for mechanical properties, will it be capable of pulling up an atomic force microscope (in the present example) or other instruments with cross capabilities?

- I'm not sure I consider "sample prep" a facility-type capability. That's more of an instrument-type capability in my mind.

- As I mentioned before, we started by building a framework based on the previous 5-8 years of DOE-NE policy documents and then casting a wide net to capture data. Now I think that we need to look at the database design from a high-level and see what works best.

- Part of the problem stems from the fact that I am a novice database programmer, so the NEID took the form that I knew how to build. The professionals are fixing that now. 
- Since instruments live in facilities that are part of institutions, perhaps the only type of entry should be the instruments. The facility and institution would just be characteristics of the instrument. The capabilities (microscopy, mechanical testing, sample preparation) would be other characteristics.

- I think that by using relational database programming, we will still be able to search for a given facility or institution and get all of the instruments therein.

- We can do a lot with the database format and structure. We should make decisions as early as possible in order to limit the amount of resampling that we need to get the extra data. Don't worry about big changes though. We should do what we need to make this as useful as possible.

- Unfortunately, I have to wait on some of these things because the database is in the hands of the programmers. They are converting it from Microsoft Access to Structured Query Language. Anything that I do locally is almost wasted effort. We should get our thoughts together though, so I can use them to guide their actions.

- I am not sure there is any value in the "material condition" category. For example, the Advanced Test Reactor (ATR) has been down for $\sim 6$ months due to a failed pressurizer, but it is listed as "excellent." Facilities are likely to be hesitant to give their own equipment a negative condition.

- Overall, consistency of responses seems to be a challenge. I understand that you are working on a facility survey, and maybe you can include specific examples of what a complete response looks like as a guide. For example, "Physical_plant" under the reactors tab has a wide array of responses for various facilities, including "sealed tube from argon cell into radiography beam," "converting to LEU," and "excellent." I'm not sure what this category is trying to convey.

- The material condition category is meant to describe the conditions of the instrument itself, or the scientific area of the laboratory/facility, namely its readiness and ability to carry out the mission. The physical plant category would be similar but applied to the rest of the facility, including the electrical supply; heating, ventilating, and air conditioning; building structure; etc. This sort of question was asked in the "Required Assets for a Nuclear Energy Applied R\&D Program (2010)" document.

- I am certainly open to modifying the format of the NEID, including the fields. I think that we should include something like these two fields, but I certainly agree that getting a frank response will be difficult.

- I still have significant quality control issues to resolve with respect to consistency of entries. In some cases, there were clear places to put certain information, in others, I put it somewhere until I could revisit it. Some of these fields were added to the NEID as I was gathering data last year. I expect that we may be able to remove several of the fields before deployment. I hope to get some part-time help to review the NEID for errors, typos, and consistency.

- There is no expectation that the NEID is the only reference for these instruments and facilities. That is why I link to the web page and provide some idea of the references used to get the data. I attached the list of references in a spreadsheet as well. 
- Have you given any thought to how you capture capabilities that may not easily fit into a facility or instrument category? For example, at Pacific Northwest National Laboratory, our partner facility agreement with NSUF includes our irradiation experiment design and fabrication capability. Both of those capabilities are dispersed around the lab in various facilities, so it's hard to categorize them unless there is a capability-based compilation.

- This is an important point. We could put this sort of thing in the database as an "instrument," but the categories for its capabilities would be different: modeling and simulation, machine shop, target fabrication, instrumentation design shop, etc.

- The high-performance computing capabilities may fit into this area.

- In some of the sheets, you have listed values for different instruments. I think the more suitable word would be "attribute."

- I have rethought the structure of the database. Instead of a facility or instrument falling into a given category, I want to have each facility or instrument stand on its own and have primary, secondary, and tertiary capabilities as fields under the instrument or facility. This is similar to the way that FIMS handles it.

- This helps remove some of the issues that I have seen raised in this review. Is a focused ion beam a microscope or a sample preparation device? It can have detectors installed to make it able to perform crystallographic or chemical analysis as well. If we just have multiple capabilities for each instrument and facility, it ends the issue.

- Users will be able to search by instrument type, capability, or both.

- I think we need one more sheet for thermal analyses, such as Laser Flash Apparatus, Differential Scanning Calorimetry, differential thermal analysis, thermal gravimetric analysis, simultaneous thermal analysis, Dilatometry, etc.

- There is a thermal analysis sheet in the instrumentation spreadsheet with that type of instrumentation.

- On the fuel fabrication page, I would like to see more instruments listed (spark plasma sintering, powder milling machines, particle size analyzer, powder flow ability tester, etc.).

- We are trying to set a cost floor for the equipment in this database. Some equipment will be left out because of this. I will try to make sure that all important equipment is recorded. I did see some of these items under sample preparation.

- I want to see x-ray diffraction, x-ray tomography, 3-D x-ray scan, or non-destructive exam each in new sheets or embedded in existing sheets.

- There is an $\mathrm{x}$-ray diffraction sheet in the instrumentation spreadsheet.

- I suggest plasma neutron sources be listed in a separate category and not as part of "reactors."

- I am redoing the whole structure of the database. Each facility and instrument will stand alone. They will have fields for primary, secondary, and tertiary capabilities. Facilities will also have ties to NE missions. This will allow users to search by mission or capability and get all of the facilities and/or instruments that match. I will elaborate in the upcoming report.

- What do the letter codes "I," "F," "T," etc. mean for "major_capability," "minor-area," and "modifiers" categories?

- I was using a coding system that I neglected to supply along with the spreadsheets. I am interested to know if the panel thinks it is still necessary in light of the changes to the NEID structure, namely adding multiple capabilities for a single instrument or facility. 
- The low-enriched uranium conversion for U.S. high performance reactors has been delayed to 2026 or later. This may not be important information to include under "physical plants" for ATR, ATR-C, etc.

- That is a fine idea since it (potentially) jeopardizes future operation of these remaining facilities.

- What are the criteria considered for "material_condition"? A few facilities are listed as "excellent," which is not apparent due to age of the facilities.

- This is a category that flows out of some older DOE documents looking at physical facilities (real estate) to meet future DOE needs. Any entries that are in there now were based on a statement in one of the references. In order to reduce errors, I am intending to get this type of data straight from the FIMS database. This is used DOE complex-wide. The data is updated quarterly and vetted through the DOE-NE facilities office. They just concluded a comprehensive review for the Secretary of Energy.

- I suggest using the word "coolant" instead of "atmosphere." Why is the High Flux Isotope Reactor listed "many"?

- "Atmosphere" was another category that went from specific (microscopes, glove boxes, and furnaces) to general. It may not fit well. I can step it back to those instruments that are appropriate. I was trying to make as many categories as possible, since that will simplify searching.

- Perhaps a solution for the database would be to have a page that briefly defines the different categories for the user.

- "Thermal flux" and "fast flux"—are these average fluxes or maximum?

- Likely maximum, but often unspecified in the references. It is best when the fluxes are given for a specific core location.

- I would also prefer a standard definition for this sort of thing (e.g., thermal $=25.4 \mathrm{meV}$, fast $\geq 1 \mathrm{MeV}$, or $0.1 \mathrm{MeV}$ ). We can include these in the detailed survey that I am intending to send out to facilities in the NEID. There will likely still be issues with conformity. Perhaps we can add a clarifier that has the definition or "unknown."

- The NEID is meant to be a relatively high-level database. We can decide what information that we want included to help the various users. It is not meant to be the only reference that a user utilizes in their search. It should enable them to narrow their search to a few facilities and give them the direction to go deeper.

- "Flow_loops" seems to mean in-core loops.

- Yes. We can certainly change the names to clarify as needed.

- Is it necessary to indicate "high security facility"?

- The issue would be access to all types of users. There is a facility in the Nevada desert that advertises itself as a user facility, but I doubt the ability of a general user to access the site. Even with a path for access, some of our foreign national users may have to wait a long time to gain access. They may be better served somewhere else.

- I suggest we include heat flux and flow rate range for thermal hydraulics facilities.

- I will do that. The original choice of fields did not anticipate these other types of facilities that we are now being directed to include. 
- General question: is it important to identify the radioactivity limits for instruments such as microscopes and neutron instruments?

- In many cases, this is likely a "facility" limit. It could be a limit for an instrument as well. We may be suited with just a rough limit for a facility unless there are very different limits for certain instruments.

- "Containment" glove boxes are typically used for specific types of materials/radioactivity. Can this information be included in the database?

- Certainly. Since I tried to make a generic set of fields for all instruments and facilities, I may have missed certain ones that are important. I will add this to the 'glove box specific' list.

- Is a complete list of all of the classifiers available? It is difficult to rate the usefulness of the data without these. For example, ATR is listed as "F" for Materials Allowed, but I can't find a description of what that means. From what I can see, your slides only had a partial listing of the classification system.

- I have attached a spreadsheet with the classifiers matrix (2-NE_Core_Capabilities_Matrix). We can move beyond this at some point, but it seemed like a good start to be able to classify these different facilities with a few characters.

- Maybe it's just a formatting or sorting thing, but the order of the categories was not the same on all the different spreadsheets. I like the final category order because it puts the instrument name on top, but some of the sheets had the instrument name buried further down the list.

- The order (which I thought that I had fixed) is based on the sorting that I had recently done in the actual Microsoft Access database. I exported that to Microsoft Excel to distribute. The database users will see something standardized. 


\section{Cost Data}

- For the three cost categories (use, maintain, and replace), I think allowing more input than just a dollar figure would be helpful.

- Are these dollars per irradiation unit?

- What is included in these costs? Without some additional context, this information may not be useful.

- These categories have proved to be troublesome. User facilities have established price lists. It may be better to just link to them. Some DOE sites have costs for the facilities and instrumentation and initial purchase or replacement costs, but few have any use charges; they just don't work this way. I am happy to use anything for these areas, but it would be nice to have something that can be compared among the different facilities.

- Once we establish use cases for the different potential users, we may see that some of this information is not needed. We cast our net very wide initially, choosing many different fields, but they may not be needed in the final product.

- How will we go about capturing the "cost per use?" It will be a very tough item to characterize because it depends on so many things (type of material, type of fuel, activity level, dispersibility, etc.). For some things, it may be straightforward, and for others it may be almost impossible to characterize in a concise way.

- Costs will be one of the most difficult fields to populate. User facilities have published price lists, but many other facilities work on a contract basis, so everything is decided ad hoc.

- We can use the best information that we can get. Perhaps we can add a flag to let users know when the value is an estimate.

- Where do we capture the facility usage/utilization information?

- There is a field for "utilization hours" in both spreadsheets. Data for facilities will also be available from FIMS. Some of this will be difficult to judge. It will be self-reported from the facility. 


\section{Online Database}

- Will we have the opportunity to test the online system before it goes live? Actually interfacing with the system would be useful. In the event any changes are recommended by the panel, it would be beneficial to do this as soon as possible.

- I know your slides had one example of a search window, but I am curious on the actual functionality of setting up searches with specific parameters, like a reactor with a coolant loop YYY and a thermal flux greater than XXX.

- Yes, of course. The system is up right now in the crudest form for testing. The URL is impac.inl.gov. It is only available inside the INL network, so I don't know if you can log in. We will figure out how to get access to the Database Review Panel members before the rollout in late June.

- We can add whatever functionality we like. The budget for development was planned to allow for this type of try-and-redo until we get something usable. One of the tasks that we need to look at is the creation of "use cases." What would a user want from the NEID? What questions would Fuel Cycle R\&D ask, or someone from different program offices at DOE? What questions would a principle investigator working on a proposal ask? (This pertains more to the public version to be released in December 2015.)

- As far as specific things like flux values, they are in the NEID, so they could be queried. It might be a challenge to make it clear to the user on how to ask the question. Some fields are currently locked to a certain data type. If you put the wrong type of information in the cell, it will reject it. This helps keep the database clean, but can also make things confusing.

- For researchers who are searching for the right facility or instrument to perform their work, how can they search for it quickly in the database?

- Do we have a search engine? Being user friendly is important.

- $\quad$ The NEID is up on an internal INL web site. I will attach a few slides of the web site's functionality. It does not yet have search capability beyond simple instrument or facility type. That will be added over the next few months as it is developed.

- I am very interested in getting "use cases" from the review panel. Think about situations where you might use the NEID. Let me know what kind of questions you come up with. We will likely have a custom ad hoc query capability, but it might only be for internal users. I would like to have a set of predefined queries for external users. There can be many of them.

- We will also have Geographical Information System mapping-based searches and visualizations. We will implement that as funding allows.

- Can the database be designed so that the entries for each facility are printed on a separate sheet for interested users?

- The "normal" mode of access for the NEID will be through the website portal. The types of reports available to the users will be guided by this committee. I will ask about that as soon as I get this report written. I will include some screenshots of the early draft web page. 
Appendix B

\section{Database Review Panel Charter}




\title{
NE Infrastructure Management Program
}

\author{
Database Review Panel Charter
}

\begin{abstract}
Purpose
In support of the Nuclear Energy Infrastructure Database (NEID) being developed by the Nuclear Science User Facilities (NSUF), a Database Review Panel (DRP) is hereby formed and chartered to review and provide advice on the development, implementation and utilization of the NEID.

Additionally, the DRP provides an expert opinion of needed infrastructure for near-, mid-, and longterm future research in support of the NE mission in accordance with established NE direction, such as the Nuclear Energy Research and Development Roadmap. Their input will be used as one of many sources supporting the gap analysis to be completed in fiscal year (FY) 2015 that will assist in providing recommendations and support for future funding opportunities.
\end{abstract}

\section{Duties}

The DRP is tasked to provide the following to the NSUF:

1. Review the structure of the database, including:

a. Types of facilities and instruments to be included in the database,

b. Types of information to be included about the facilities and instruments in the database,

c. Layout and usability of the database.

2. Review the contents of the database, including:

a. Missing facilities or instruments,

b. Errors in data entered in the database.

3. Provide an expert opinion of needed infrastructure for future research in support of the NE mission (for utilization as one source in the capability gap analysis).

4. Provide preliminary input on possible implementation strategies for future NSUF management of NE-associated research and development infrastructure. 


\section{Meetings}

It is expected that the work of this panel can generally be performed remotely via teleconference and email. This will have the advantage of reducing costs for NSUF/DOE and additional burdens on committee members. Prior to the submission of each report, the DRP will hold at least one remote interactive meeting to discuss the panel's findings and the content of the report. One physical meeting will be held at the annual NSUF User's Week meeting. Ad hoc meetings may be held at advantageous times, such as professional conferences where a majority of the panel is in attendance for other business.

\section{Membership}

The panel shall be comprised of five members with expertise in nuclear energy-associated research. It is intended that they represent the major constituencies associated with nuclear energy research: academia, industry, research reactor, national laboratory, and Department of Energy program management. The panel will be chaired by the NSUF Research and Development Infrastructure Lead (Dr. Brenden Heidrich).

In their representation of the constituencies listed above, it is anticipated that a portion of the DRP membership will come from the NSUF User's Organization Executive Committee or the Capabilities and Infrastructure Committee. Other members of the DRP, in addition to the chair, will come from DOE and/or other external groups. The chair shall recommend changes to the DRP membership for NE-4 approval as needed. The DRP membership for FY 2015 is listed in Table 1.

Table 1: FY 2015 NSUF NE Infrastructure Database Review Panel Membership*

\begin{tabular}{|c|c|c|}
\multicolumn{1}{c}{ Name } & \multicolumn{1}{c}{ Institution } & Constituency \\
\hline Brenden Heidrich & Idaho National Laboratory & DOE \\
\hline Jason Tokey & DOE-Office of Nuclear Energy & National Laboratory \\
\hline Dave Senor & Pacific Northwest National Laboratory & Industry \\
\hline Peng Xu & Toshiba-Westinghouse & University \\
\hline Lin-wen Hu & Massachusetts Institute of Technology & \\
\hline
\end{tabular}

*Peter Hosemann from University of California Berkeley will act as an alternate in the event a member cannot complete their duties 


\section{FY 2015 Deliverables}

The DRP membership will provide input and feedback to the R\&D Infrastructure Lead, who will generate two reports based on the panel's work. The reports will be reviewed by the NSUF Director.

Report

Completion Date

1. DRP NE Infrastructure Database Fitness and Suitability Report

- Fitness of the data included in the NEID

$2 / 27 / 2015$

- Suitability of the structure of the NEID

2. DRP NE R\&D Capability Needs Report

DRP members' expert opinions regarding the infrastructure requirements to support the near-, mid-, and long-term future Nuclear

$4 / 30 / 2015$ Engineering research.

\section{DRP Activities for FY 2015}

Event or Task

\begin{tabular}{|l|c|}
\hline DRP formed and charter approved by: DOE (NE-4), NSUF Director and panel & $1 / 30 / 2015$ \\
members, as appropriate. & $2 / 27 / 2015$ \\
chair. Dr. Heidrich generates NEID fitness and suitability report. & $3 / 15 / 2015$ \\
\hline Dr. Heidrich provides support to NEUP/NEET infrastructure application review & \\
using database and other supporting resources, including DRP opinions as & $4 / 30 / 2015$ \\
appropriate. & $6 / 5 / 2015$ \\
\hline Panel provides expert opinion of R\&D direction and capability needs to the chair. & \\
Dr. Heidrich generates the DRP NE R\&D Capability Needs Report. & $6 / 22 / 2015$ \\
\hline Dr. Heidrich presents summary of DRP efforts to the Department of Energy & \\
Office of Science and Technology Innovation (NE-4). & \\
\hline Dr. Heidrich presents summary of DRP efforts to the NSUF Scientific Review & \\
\hline Board and User's Organization during User's Week. & \\
\hline
\end{tabular}


Due to the evolving nature of the Infrastructure Management Program (IMP), a revised DRP Charter will be generated each year to reflect the current program direction, as part of the annual NEID program review process.

Approval

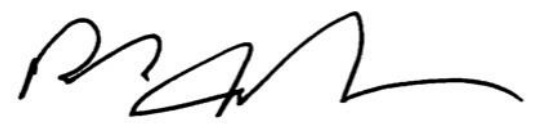

R. Shane Johnson, Deputy Assistant Secretary for Science and Technology Innovation Office of Nuclear Energy

\section{$1 / 28 / 15$}

Date 